\title{
Putaminal Mosaic Visualized by Tyrosine Hydroxylase Immunohistochemistry in the Human Neostriatum
}

\author{
Ryoma Morigaki ${ }^{1,2,3}$ and Satoshi Goto 1,2* \\ ${ }^{1}$ Department of Neurodegenerative Disorders Research, Institute of Biomedical Sciences, Graduate School of Medical \\ Sciences, Tokushima University, Tokushima, Japan, ${ }^{2}$ Parkinson's Disease and Dystonia Research Center, Tokushima \\ University Hospital, Tokushima University, Tokushima, Japan, ${ }^{3}$ Department of Neurosurgery, Institute of Biomedical Sciences, \\ Graduate School of Medical Sciences, Tokushima University, Tokushima, Japan
}

OPEN ACCESS

Edited by:

Yun-Qing Li,

The Fourth Military Medical

University, China

Reviewed by:

Jill Crittenden,

Massachusetts Institute of

Technology, USA

Javier Blesa,

Centro Integral de Neurociencias

(CINAC), Spain

*Correspondence:

Satoshi Goto

sgoto@tokushima-u.ac.jp

Received: 10 January 2016

Accepted: 14 March 2016

Published: 05 April 2016

Citation:

Morigaki R and Goto S (2016)

Putaminal Mosaic Visualized by

Tyrosine Hydroxylase

Immunohistochemistry in the Human

Neostriatum.

Front. Neuroanat. 10:34.

doi: 10.3389/fnana.2016.00034
Among the basal ganglia-thalamocortical circuits, the putamen plays a critical role in the "motor" circuits that control voluntary movements and motor learning. The human neostriatum comprises two functional subdivisions known as the striosome (patch) and matrix compartments. Accumulating evidence suggests that compartment-specific dysregulations of dopamine activity might be involved in the disease-specific pathology and symptoms of human striatal diseases including movement disorders. This study was undertaken to examine whether or how striatal dopaminergic innervations are organized into the compartmentalized architecture found in the putamen of adult human brains. For this purpose, we used a highly sensitive immunohistochemistry (IHC) technique to identify tyrosine hydroxylase (TH; EC 1.14.16.2), a marker for striatal dopaminergic axons and terminals, in formalin-fixed paraffin-embedded (FFPE) tissues obtained from autopsied human brains. Herein, we report that discrete compartmentalization of TH-labeled innervations occurs in the putamen, as in the caudate nucleus (CN), with a higher density of TH labeling in the matrix compared to the striosomes. Our results provide anatomical evidence to support the hypothesis that compartmentspecific dysfunction of the striosome-matrix dopaminergic systems might contribute to the genesis of movement disorders.

Keywords: putamen, matrix compartment, striosomes, tyrosine hydroxylase, human brain, immunohistochemistry

\section{INTRODUCTION}

The human neostriatum comprising the caudate nucleus $(\mathrm{CN})$ and putamen is the primary input region of the basal ganglia, a group of subcortical nuclei that control a wide range of sensorimotor, cognitive and emotional functions (for review see, Graybiel, 2008; Amemori et al., 2011). It has so far been known that the basal ganglia are organized into several structurally and functionally distinct neural circuits that link the cortex, basal ganglia, and thalamus, with each circuit focused on a different frontal cortex territory (Alexander et al., 1986, 1990). Among these basal gangliathalamocortical circuits, the putamen participates in the "motor" circuits and is thereby important to basal ganglia motor control and movement disorders (Albin et al., 1989; DeLong, 1990). Parkinson's disease (PD) results from a striatal dopamine deficiency due to the neurodegenerative 
loss of dopamine-producing cells in the substantia nigra pars compacta (SNc; Hirsch et al., 1988). Kish et al. (1988) showed that the depletion of dopamine in patients with PD was most remarkable in the putamen, particularly in its caudal portions. Goto et al. (1989a, 1996) also documented that in parkinsonian patients, a pathological lesion was found specifically in the nigrostriatal loop that forms a link with the putamen.

The mammalian neostriatum is composed of two functional subdivisions known as the striosome (patch) and matrix compartments, which are developmentally, anatomically, and biochemically distinct (Graybiel and Ragsdale, 1978; Bolam et al., 1988; Graybiel, 1990; Gerfen, 1992). The striosome and matrix compartments make up about $15 \%$ and $85 \%$ of the volume of the striatum, respectively, in mammalian brains (Johnston et al., 1990). Although single dopaminergic afferent axons can terminate in both the compartments (Matsuda et al., 2009), the striosomes and matrix tend to receive dopaminergic afferents from distinct groups of SNc neurons. The striosomal cells are preferentially innervated by a group of dopamine-producing cells in the ventral tier of the SNc (Gerfen et al., 1987; Jimenez-Castellanos and Graybiel, 1987; Langer and Graybiel, 1989; Prensa and Parent, 2001), while the matrix cells preferentially receive the afferents arising from dopaminergic cells in the dorsal tier of the SNc, the ventral tegmental area and the retrorubral area (Gerfen et al., 1987; Jimenez-Castellanos and Graybiel, 1987; Prensa and Parent, 2001).

Accumulating evidence suggests that striosome-matrix dopaminergic systems exert a critical role in basal gangliathalamocortical circuits (Graybiel, 2008; Amemori et al., 2011). Interestingly, imbalanced dopamine activity between the striosome and matrix compartments has been suggested to underlie the genesis of pathological lesions and clinical symptoms that occur in multiple movement disorders (Graybiel, 2008; Goto et al., 2010; Crittenden and Graybiel, 2011), such as the L-DOPA-induced dyskinesia associated with PD (Graybiel et al., 2000). However, despite previous immunohistochemical studies using frozen sections (Ferrante and Kowall, 1987; Graybiel et al., 1987; Holt et al., 1997; Ciliax et al., 1999; Prensa et al., 1999, 2000), it remains undetermined whether or how striatal dopaminergic innervations might be organized into a discrete striosome-matrix axis in the human putamen.

To address this issue, we employed a highly-sensitive immunohistochemistry (IHC) method (Goto et al., 2015) to identify tyrosine hydroxylase (TH; EC 1.14.16.2) in formalinfixed paraffin-embedded (FFPE) striatal tissues from autopsied human brains. $\mathrm{TH}$ serves as a reliable marker for visualizing dopaminergic axons and terminals in the striatum (Moss and Bolam, 2008). Here, we show that as in the $\mathrm{CN}$, discrete compartmentalization of $\mathrm{TH}$ immunoreactivity occurs in the putamen, with a higher density of $\mathrm{TH}$ labeling in the matrix compartment relative to the striosomes. Our results provide anatomical evidence to support the hypothesis that compartment-specific dysfunction of the striosome-matrix dopaminergic systems might contribute to the genesis of human movement disorders.

\section{MATERIALS AND METHODS}

\section{Western Blot Analysis on Mouse Brains}

All procedural protocols that involve mouse experiments were approved by the Ethical Review Committee of the Tokushima University. We used male C57BL/6 mice (Nihon SLC Co., Shizuoka, Japan; $n=3$ ) aged $8-10$ weeks. Western blot analysis was performed with a rabbit polyclonal antibody against TH (Sato et al., 2008), according to the method that we previously ported (Morigaki and Goto, 2015). Blots were developed by chemiluminescent autoradiography (ECL plus kit; GE Healthcare, Buckingham, UK).

\section{IHC for TH in Mouse Brains}

After receiving an intraperitoneal injection of a lethal dose of pentobarbital (Sigma-Aldrich, St. Louis, MO, USA), mice $(n=5)$ were transcardially perfused with cold PBS, and followed by cold $4 \%$ paraformaldehyde in $0.1 \mathrm{M}$ phosphate buffer ( $\mathrm{pH} 7.2$ ). Frozen sections with $16-\mu \mathrm{m}$ thickness were processed for the IHC with the tyramide signal amplification (TSA) technique in a freefloating manner, as in our previous reports (Okita et al., 2012; Morigaki and Goto, 2015). Briefly, rabbit polyclonal antibody against TH $(1: 100,000)$ was used as a primary antibody. To detect the bound antibody, we used the Histofine Simple Stain Kit (Nichirei, Tokyo, Japan) and the TSA Plus Cyanine 3 System (Perkin Elmer, Shelton, CT, USA).

\section{Human Brain Tissue Preparation for IHC}

All procedural protocols that involve autopsied human brains were approved by the Ethical Review Committee of the Tokushima University. FFPE striatal sections with $4-\mu \mathrm{m}-$ thickness were prepared from the autopsied brain tissues of neurologically-normal patients $(n=5$; mean age \pm SEM, $59 \pm 8$ years), as we previously described (Morigaki and Goto, 2015). After deparaffinization and rehydration, all sections were treated with $1 \% \mathrm{H}_{2} \mathrm{O}_{2}$ in water for $5 \mathrm{~min}$. For the antigen retrieval, they were then immersed in $0.01 \mathrm{M}$ sodium citrate buffer $(\mathrm{pH}$ 6.0 ) and placed in a $700-\mathrm{W}$ microwave for $15 \mathrm{~min}$. Endogenous binding sites for avidin and biotin were blocked by using the Avidin/Biotin Blocking Kit (Vector, Burlingame, CA, USA). The sections were then immersed in 3\% BSA-PBS for $60 \mathrm{~min}$ and they were processed for the IHC protocols described below.

\section{IHC with 3,3'-Diaminobenzidine (DAB) in Human Brain Tissue}

The sections were incubated for $18 \mathrm{~h}$ in $3 \%$ BSA-PBS containing a rabbit polyclonal antibody against $\mathrm{TH}$ (1:200,000; Sato et al., 2008) or [Met]-enkephalin (MEnk; 1:500,000; Millipore, St. Louis, MO, USA; Goto et al., 2015). They were then processed for a hybrid IHC protocol that implements aspects of both the polymer-staining and avidin-biotin-complex (ABC) methods combining with the biotin-TSA system, as we previously reported (Goto et al., 2015). Briefly, the sections were incubated for $30 \mathrm{~min}$ in the polymer-staining solution (Histofine Simple Stain Kit; Nichirei). After several rinses in PBS, they were incubated for 30 min with biotinyl TSA solution prepared from a TSA Biotin 


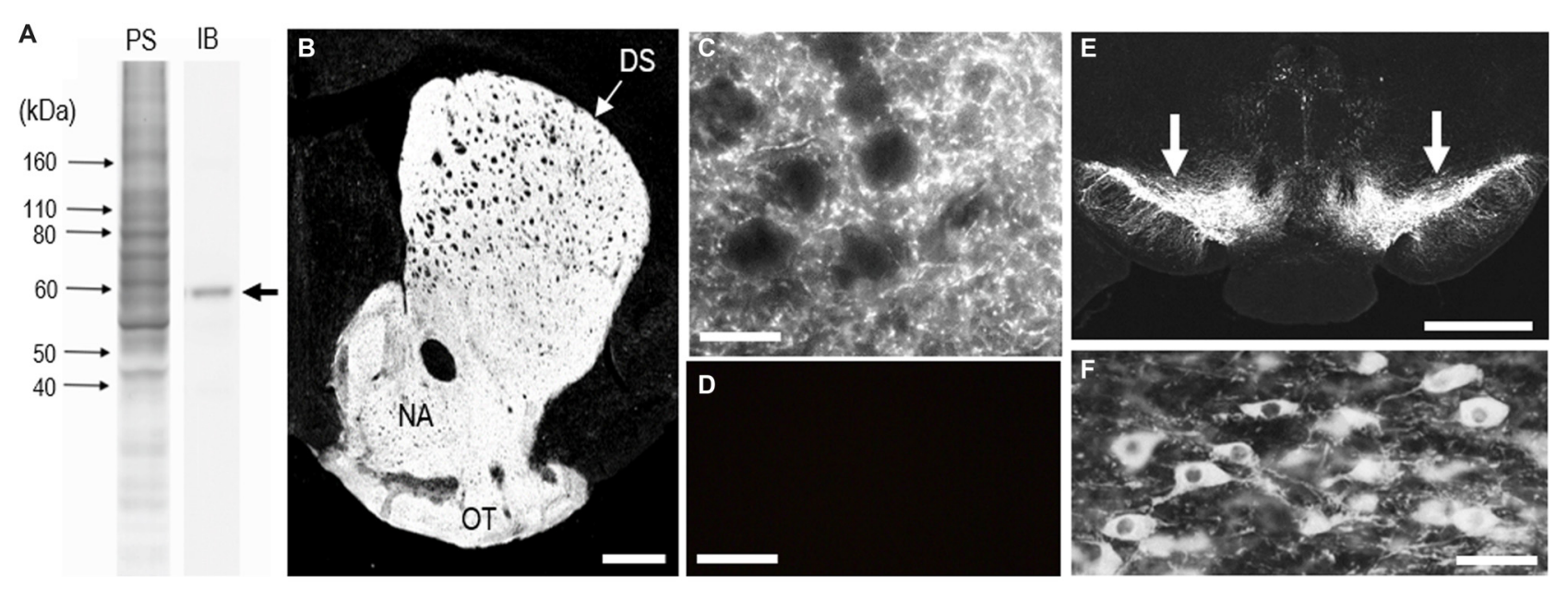

FIGURE 1 | Identification of tyrosine hydroxylase (TH) in the mouse striatum. (A) Western blot assay. Crude homogenates of protein (10 $\mu$ g) from the mouse striatum were separated on a 10\% gel by SDS-PAGE and then immunoblotted using anti-TH antibody. An immunostained protein band (arrow) was selectively detected, with an approximate molecular mass corresponding to the predicted size of native TH protein. PS, protein staining; IB, immunoblot. (B) Photomicrograph of a striatal section stained for TH. TH immunoreactivity appears to be homogeneously distributed throughout the dorsal striatum (DS). (C) Photomicrograph of the striatal area stained for TH. Numerous tiny TH-positive dots were found in the striatum. (D) Photomicrograph of the DS processed using the immunostaining protocol without anti-TH antibody. (E) Photomicrograph of the midbrain stained for TH. Arrows indicate the substantia nigra pars compacta (SNc). (F) Photomicrograph of nigral dopaminergic cells positive for TH. Abbreviations: DS, dorsal striatum; NA, nucleus accumbens; OT, olfactory tubercle. Scale bars: (B) $500 \mu \mathrm{m}$, (C,D) $20 \mu \mathrm{m}$, (E) $1 \mathrm{~mm}$, (F) $50 \mu \mathrm{m}$.

System kit (Perkin Elmer) with $1 \times$ Plus Amplification Diluent (Perkin Elmer). After several rinses in PBS, they were incubated for 30 min with the $A B C$ reagent prepared from a Vectastain Elite $\mathrm{ABC}$ kit (Vector). After several rinses in PBS, the sections were immersed for $10 \mathrm{~min}$ in $0.05 \mathrm{M}$ Tris- $\mathrm{HCl}$ ( $\mathrm{pH}$ 7.4) containing $0.05 \%$ diaminobenzidine (DAB; Merck, Darmstadt, Germany) and $0.01 \% \mathrm{H}_{2} \mathrm{O}_{2}$. After dehydration, the sections stained with DAB were cover-slipped with Malinol (Muto Pure Chemicals, Tokyo, Japan).

\section{IHC with Fluorescents in Human Brain Tissue}

The sections were first incubated for $18 \mathrm{~h}$ in 3\% BSA-PBS containing rabbit polyclonal antibody against TH (1:100,000; Sato et al., 2008). After several rinses in PBS, the bound antibodies were visualized by using the Histofine Simple Stain Kit (Nichirei) and the TSA Plus Cyanine3 System (Perkin Elmer). The sections were then treated for $30 \mathrm{~min}$ in $0.1 \mathrm{M}$ glycine- $\mathrm{HCl}$ ( $\mathrm{pH}$ 2.2) to remove the first primary antibodies. After several rinses in PBS, they were incubated for $18 \mathrm{~h}$ in $3 \%$ BSA-PBS containing rabbit polyclonal antibody against MEnk (1:200,000; Millipore) or dopamine and cAMP-regulated phosphoprotein of 32 kDa (DARPP-32; 1:20,000; Cell Signaling, Denver, MA, USA). The bound antibodies were visualized by using the Histofine Simple Stain Kit (Nichirei) and the TSA Plus Fluorescein System (Perkin Elmer; Morigaki and Goto, 2015).

\section{Digital Imaging and Morphometric Analysis}

To capture macroscopic images, we used an Epson ES-2200 color image scanner (SEIKO EPSON Co., Nagano, Japan).
Microscopic images were captured using an Olympus BX51 microscope (Olympus, Tokyo, Japan) equipped with a digital camera DP40 (Olympus). By means of Adobe Photoshop CS4, all captured images were digitally processed with minimal adjustments to contrast, brightness, and color balance.

Morphometric analysis was performed using an imageanalyzer (MetaMorph, Molecular Device, Tokyo, Japan). We measured the optical density of $\mathrm{TH}$-immunoreactive products in the striosome and matrix subfields represented by gray levels on non-colored digital images at low magnification, as previously reported (Sato et al., 2008; Morigaki and Goto, 2015). For each human striatum $(n=5)$, we measured five striatal subfields of the $\mathrm{CN}$, rostral putamen, and caudal putamen.

We also measured the striosomal areas delineated by faint $\mathrm{TH}$ staining or dense MEnk staining in the $\mathrm{CN}(n=5)$, rostral putamen $(n=5)$, and caudal putamen $(n=5)$ from each autopsied brain $(n=5)$. The mean values were used to quantify the percentage of the striatal area occupied by the striosome compartment.

To determine the cell density, we counted the numbers of neurons positive for TH or DARPP-32 in a $1 \mathrm{~mm} \times 1 \mathrm{~mm}$ field in the human neostriatum, as described in our previous report (Goto et al., 2013). We examined five fields selected randomly in each of the $\mathrm{CN}$ and putamen from each patient $(n=5)$.

\section{Statistical Analysis}

All quantitative data are presented as the mean \pm SEM. Two-group comparisons were made using the Student's $t$-test 

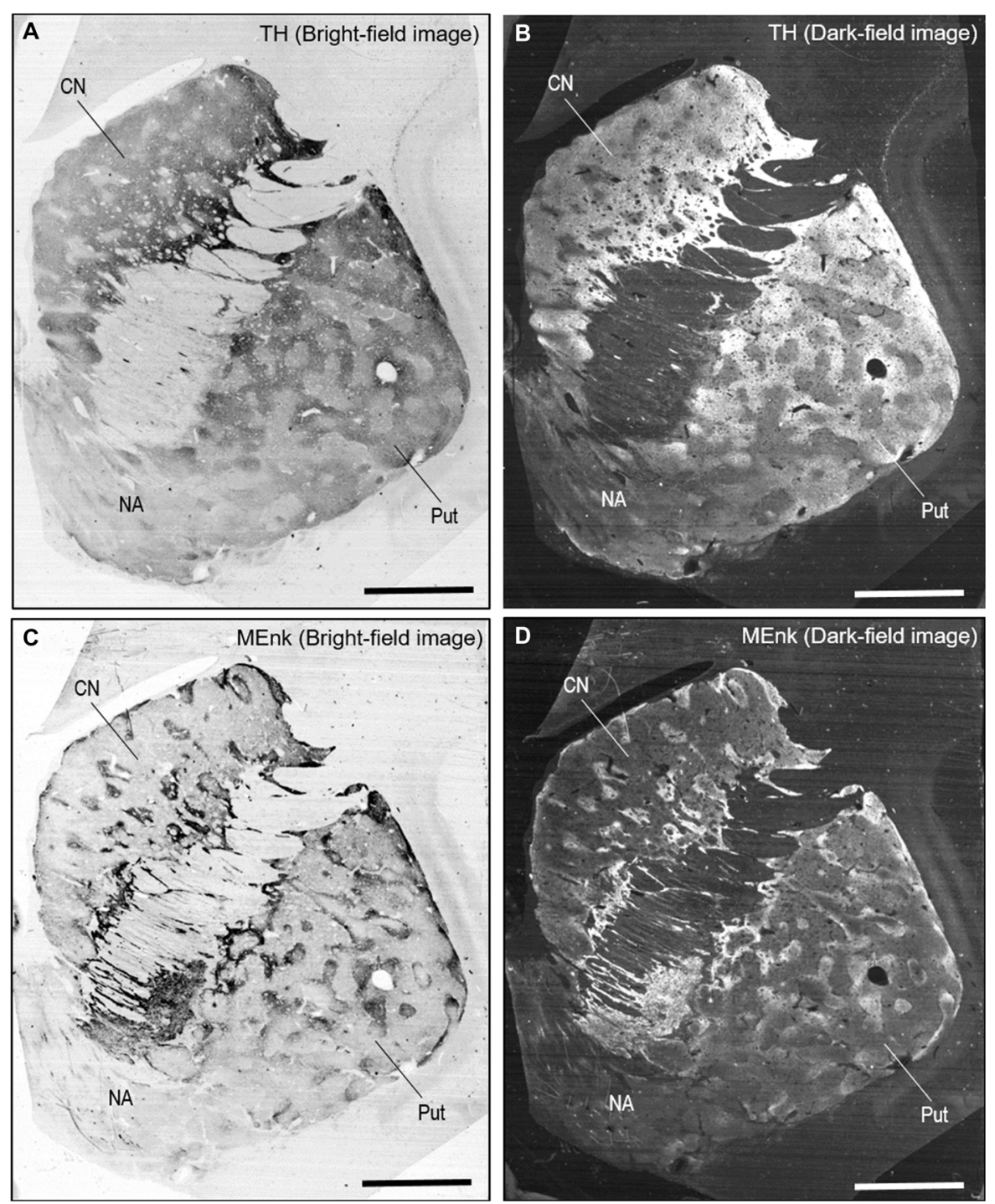

FIGURE 2 | Non-homogeneous distribution of TH in the human neostriatum. (A,B) Bright-field (A) and dark-field (B) images taken from a frontal section of the striatum stained with diaminobenzidine (DAB) for TH. (C,D) Bright-field (C) and dark-field (D) images taken from a frontal section of the striatum stained with DAB for [Met]-enkephalin (MEnk), a marker for striosomes (patches). Note that they are contiguous to those shown in (A,B). Abbreviations: CN, caudate nucleus; Put, putamen; NA, nucleus accumbens. Scale bars: $5 \mathrm{~mm}$.

(two-tailed, paired). Significant differences were considered as $P<0.05$.

\section{RESULTS}

\section{Immunochemical Detection of TH in Mouse Brains}

To determine the monospecificity of the anti- $\mathrm{TH}$ antibody used here, we first performed a western-blot analysis of the mouse brains. Immunoblots (IBs) of mouse striatal extracts showed a single protein band with an approximate molecular mass that corresponds to the predicted size of native $\mathrm{TH}$ protein (Figure 1A). The staining specificity was also assessed on frozen striatal sections from adult mouse brains with or without anti-TH antibody (Figures 1B-D). In the presence of the antibody, specific $\mathrm{TH}$ staining was detected in the striatum (Figure 1B), where numerous TH-positive puncta were densely found (Figure 1C). In agreement with our previous report (Sato et al., 2008), the distribution of $\mathrm{TH}$ labeling was diffuse and homogeneous throughout the striatum in adult mice. By contrast, $\mathrm{TH}$ immunoreactivity was not seen in striatal sections processed for the IHC protocol in the absence of the antibody (Figure 1D). In addition, strong $\mathrm{TH}$ labeling was also seen in the midbrain (Figure 1E), where $\mathrm{SNc}$ neurons exhibited intense $\mathrm{TH}$ immunoreactivity in their cell bodies and neurites (Figure 1F). 

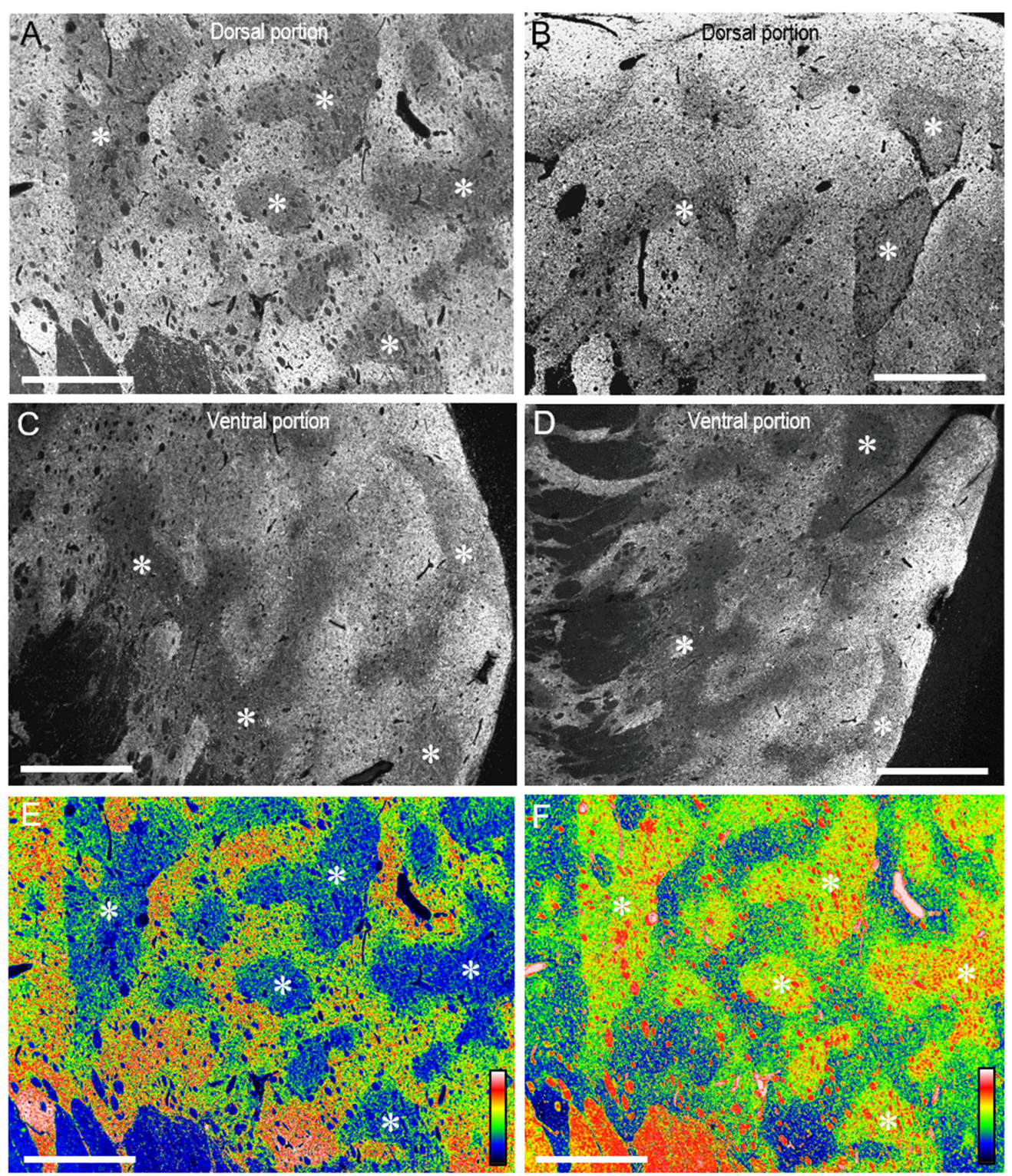

FIGURE 3 | Mosaic pattern of TH-immunostaining in the rostral putamen of the human brains. (A-D) Photomicrographs of the dark-field images taken from the dorsal $\mathbf{( A , B )}$ and ventral portions $\mathbf{( C , D )}$ of the rostral putamen stained with DAB for $\mathrm{TH}$. Asterisks indicate examples of striatal subfields with sparse TH labeling. (E,F) Graded color-converted representations of dark-field (E) and bright-field (F) images of the striatal area stained with DAB for TH, which is shown in (A). A standard pseudocolor scale from blue (lowest level) through green, yellow, red, and white (highest level) was used. Asterisks indicate examples of corresponding zones poor in TH-labeling. Scale bars: $2 \mathrm{~mm}$.

\section{Putaminal Mosaic Pattern Visualized by TH-Immunostaining with DAB in Human Brains}

A highly-sensitive IHC technique (Goto et al., 2015) allowed us to detect TH immunoreactivity in FFPE human autopsy tissue. Specific TH labeling was identified in the neostriatum composed of the $\mathrm{CN}$ and putamen. No TH labeling was detected in striatal sections processed for the IHC protocol without the anti-TH antibody. Bright-field (Figure 2A) and dark-field (Figure 2B) images are shown of a striatal section stained with $\mathrm{DAB}$ for $\mathrm{TH}$. These macroscopic images reveal that in both the $\mathrm{CN}$ and putamen, $\mathrm{TH}$ labeling is distributed in a non-homogeneous pattern of low- and high-imunoreactive zones. Notably, patches of low $\mathrm{TH}$ immunoreactivity were evident in the putamen, as in the $\mathrm{CN}$.

On FFPE striatal tissue obtained from autopsied human brains, MEnk is one of the most reliable IHC markers for visualizing striatal compartments with higher density of MEnk 

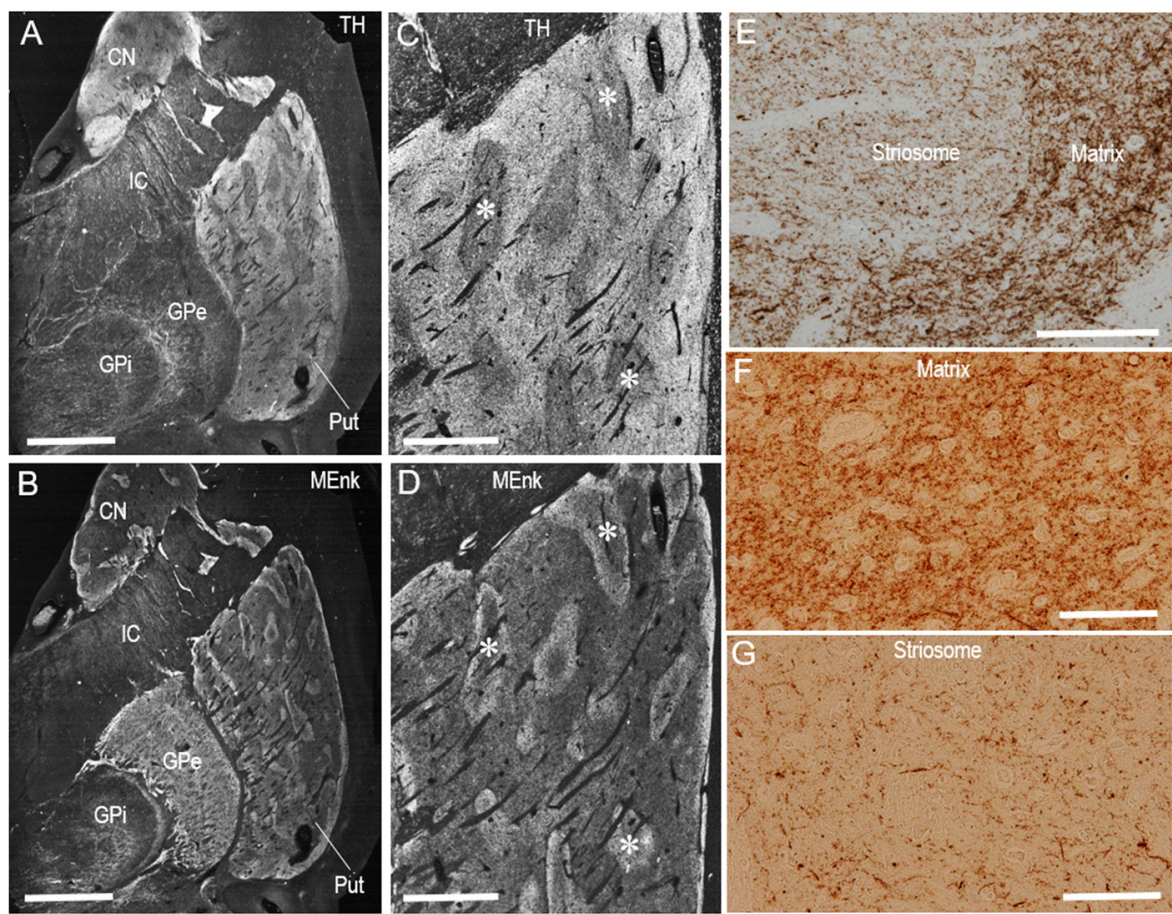

FIGURE 4 | Compartmental distribution of TH immunoreactivity in the caudal putamen of the human brains. (A-D) Serial-section analysis of dark-field images of the lenticular nucleus (A,B) and caudal putamen (C,D) stained with DAB for TH $(\mathbf{A}, \mathbf{C})$ and MEnk (B,D). Asterisks indicate examples of corresponding striosomes. (E) Photomicrograph at the border between the striosome and matrix in a putaminal area stained with DAB for TH. (F,G) Photomicrographs of the matrix (F) and striosome (G) in the putamen stained with DAB for TH. Note that the matrix area revealed a greater density of TH-positive fibers and puncta, compared with the striosomal area. Abbreviations: CN, caudate nucleus; Put, putamen; GPe, globus pallidus externa; GPi; globus pallidus interna; IC, internal capsule. Scale bars: (A,B) $5 \mathrm{~mm}, \mathbf{( C , D )} 2 \mathrm{~mm}$, (E) $500 \mu \mathrm{m}, \mathbf{( F , G ) ~} 100 \mu \mathrm{m}$.

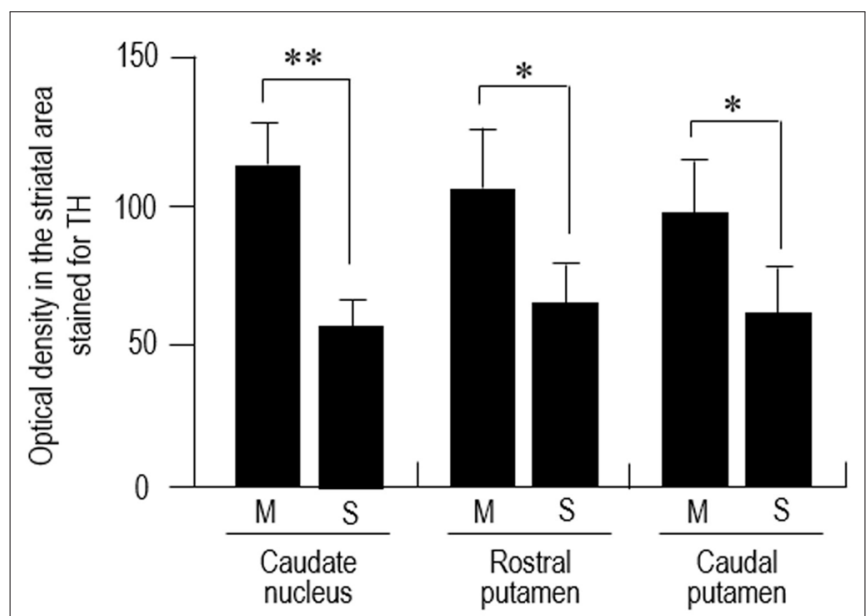

FIGURE 5 | Densitometric analysis of the human striatum stained for TH. Measurements of the optical density of $\mathrm{TH}$-immunoreactive DAB products were performed in the striosome (S) and matrix (M) compartments of the $\mathrm{CN}$, rostral putamen and caudal putamen. Data represent means \pm SEM (bars), $n=25$. ${ }^{*}$ indicates $P=0.01, \mathrm{M}$ vs. S; *indicates $P=0.05, \mathrm{M}$ vs. S.

labeling in the striosomes than in the matrix (Goto et al., 2013, 2015). Bright-field and dark-field images of a striatal section stained with DAB for MEnk are shown in Figures 2C,D, respectively. Contiguous sections stained for $\mathrm{TH}$ (Figures 2A,B) and MEnk (Figures 2C,D) show a correspondence between zones of low TH labeling and those of heightened MEnk labeling in both the $\mathrm{CN}$ and putamen.

On dark-field microscopic images with low magnification, compartmental patterning of $\mathrm{TH}$ labeling was found in the rostral putamen (Figures 3A-D). A mosaic pattern of lowand high-immunoreactive zones that varied in their shapes and sizes was seen in both the dorsal (Figures 3A,B) and ventral (Figures 3C,D) portions of the rostral putamen. This was also evident in the graded color-converted images of dark-field (Figure 3E) and bright-field (Figure 3F) images of the putaminal area shown in Figure 3A.

Dark-field macroscopic images of contiguous sections of the lenticular nucleus stained with $\mathrm{DAB}$ for $\mathrm{TH}$ and MEnk are shown in Figures $\mathbf{4 A , B}$, respectively. They represent the complementary distribution of $\mathrm{TH}$ and MEnk in the caudal portion of the putamen. Microscopic images with low magnification (Figures 4C,D) also show a striking correspondence between the $\mathrm{TH}$-poor zones and the MEnkrich striosomes. A photomicrograph of the border between the striosome and matrix areas (Figure 4E) shows less dense TH immunoreactivity in the striosome compared to the matrix. Higher-magnification images also demonstrate that the matrix area contains a greater density of $\mathrm{TH}$-positive fibers and puncta 

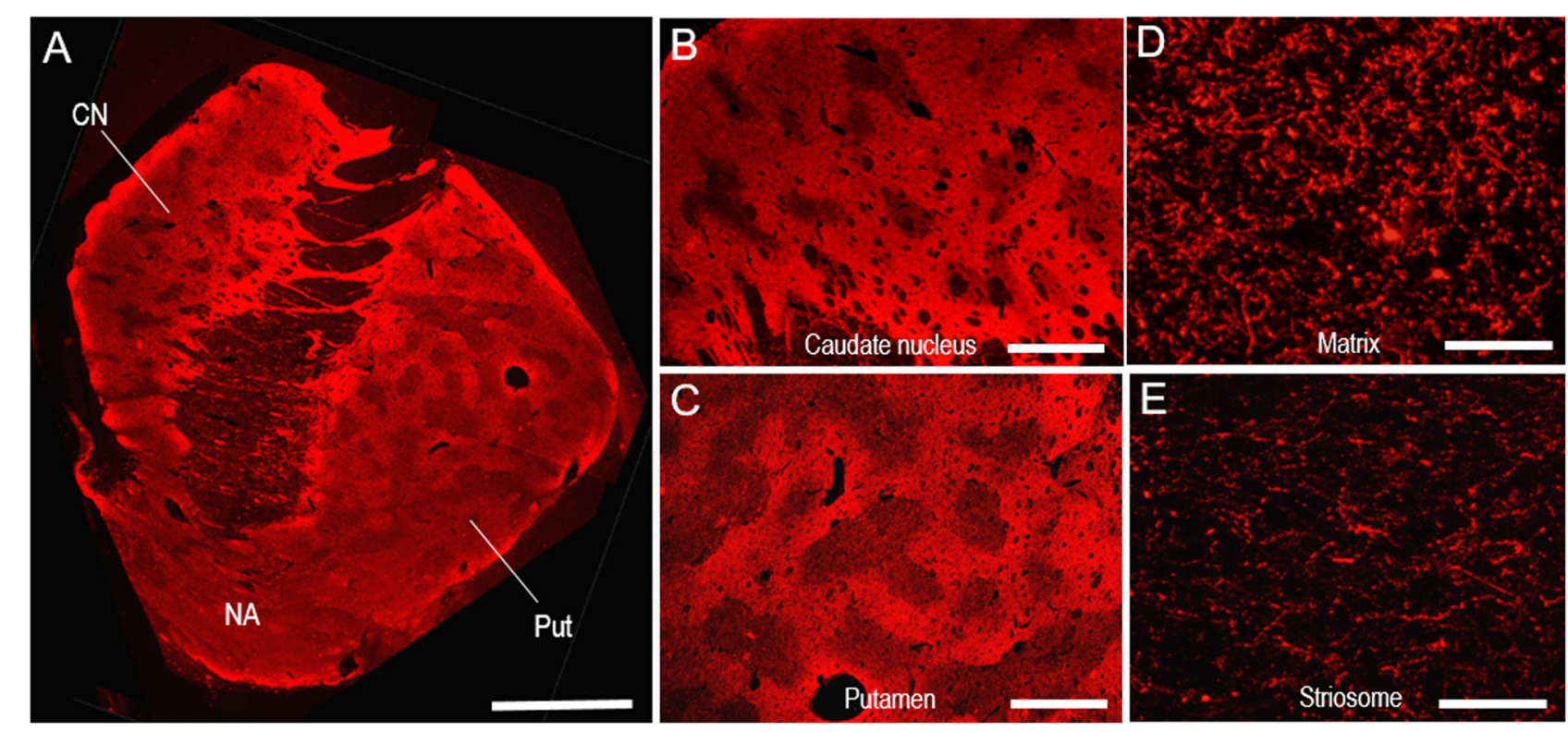

FIGURE 6 | Neostriatal mosaic visualized by TH-immunostaining with Cyanine 3 in human brains. (A) A photomontage of a striatal section stained for TH (B,C) Photomicrographs of the CN (B) and putamen (C) in the striatum stained for TH. (D,E) Photomicrographs of areas stained for TH in the matrix (D) and striosome (E) of the putamen. Abbreviations: CN, caudate nucleus; Put, putamen; NA, nucleus accumbens. Scale bars: (A) $5 \mathrm{~mm},(\mathbf{B}, \mathbf{C}) 2 \mathrm{~mm},(\mathbf{D}, \mathbf{E}) 50 \mu \mathrm{m}$.
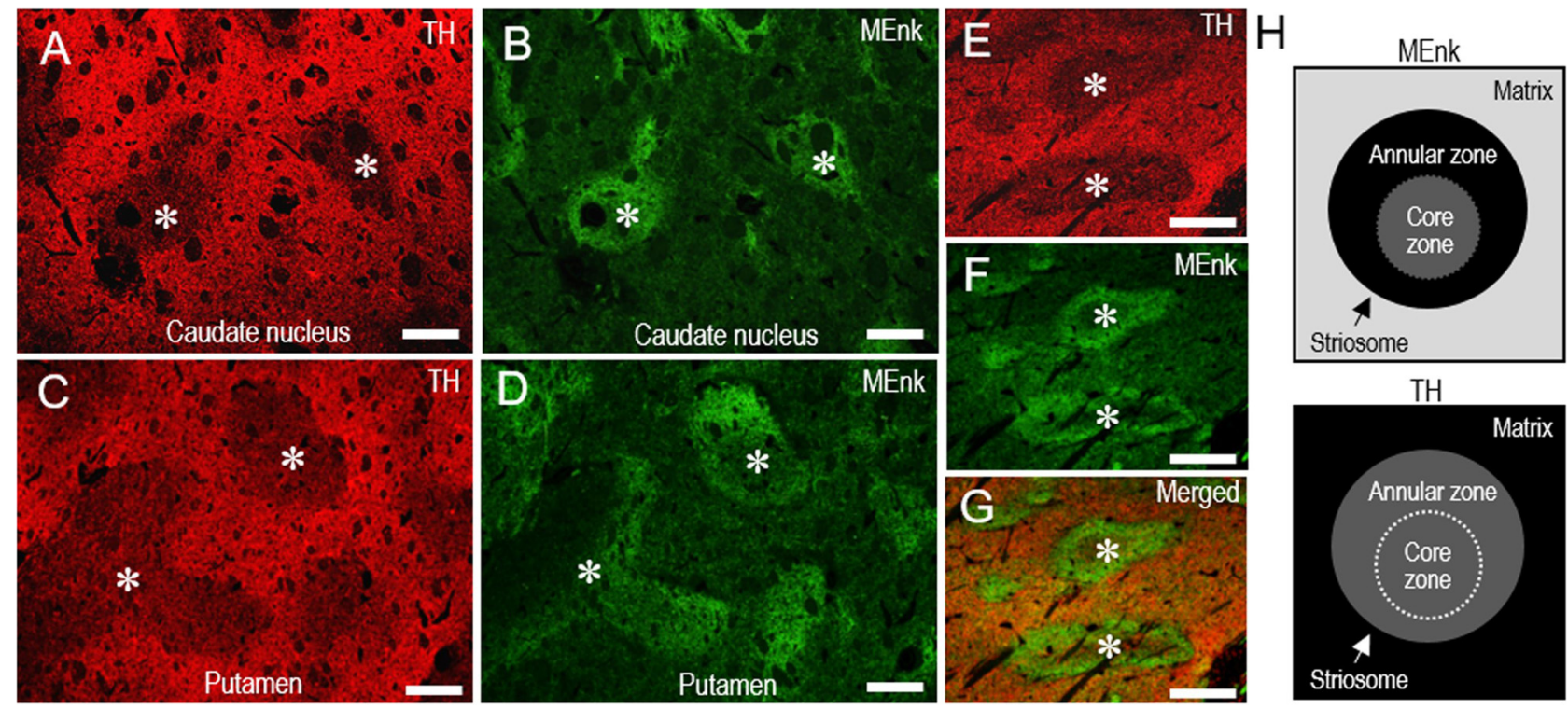

FIGURE 7 | Pattern of localization of TH in the striosome-matrix domains of the human neostriatum. (A-D) Photomicrographs of the CN (A,B) and putamen (C,D) double-stained for TH $(\mathbf{A}, \mathbf{C})$ and MEnk (B,D). Corresponding striosomes are indicated by asterisks. (E-G) Photomicrographs of an area of the putamen double-stained for TH $(\mathbf{E})$ and MEnk (F), with a merged image (G). Corresponding striosomes are indicated by asterisks. Note that the margins of the TH-poor zones correspond to the outer margins of the striosomes enriched in MEnk. (H) Depicted are the patterns of localization of MEnk (upper) or TH (lower) in the striosome-matrix system. The striosome consists of annular and core zones. Higher densities of TH or MEnk-immunoreactive products are indicated by higher gray-scale levels. Scale bars: (A-D) $500 \mu \mathrm{m},(\mathbf{E}-\mathbf{G}) 250 \mu \mathrm{m}$

(Figure 4F), compared with the striosomal area (Figure 4G). To confirm this visual impression, the optical density was measured on areas of the striosome and matrix in the $\mathrm{CN}$, rostral putamen, and caudal putamen (Figure 5). The results showed that in all the striatal areas examined, the density of TH-labeling in the matrix was significantly higher than that in the striosomes. 

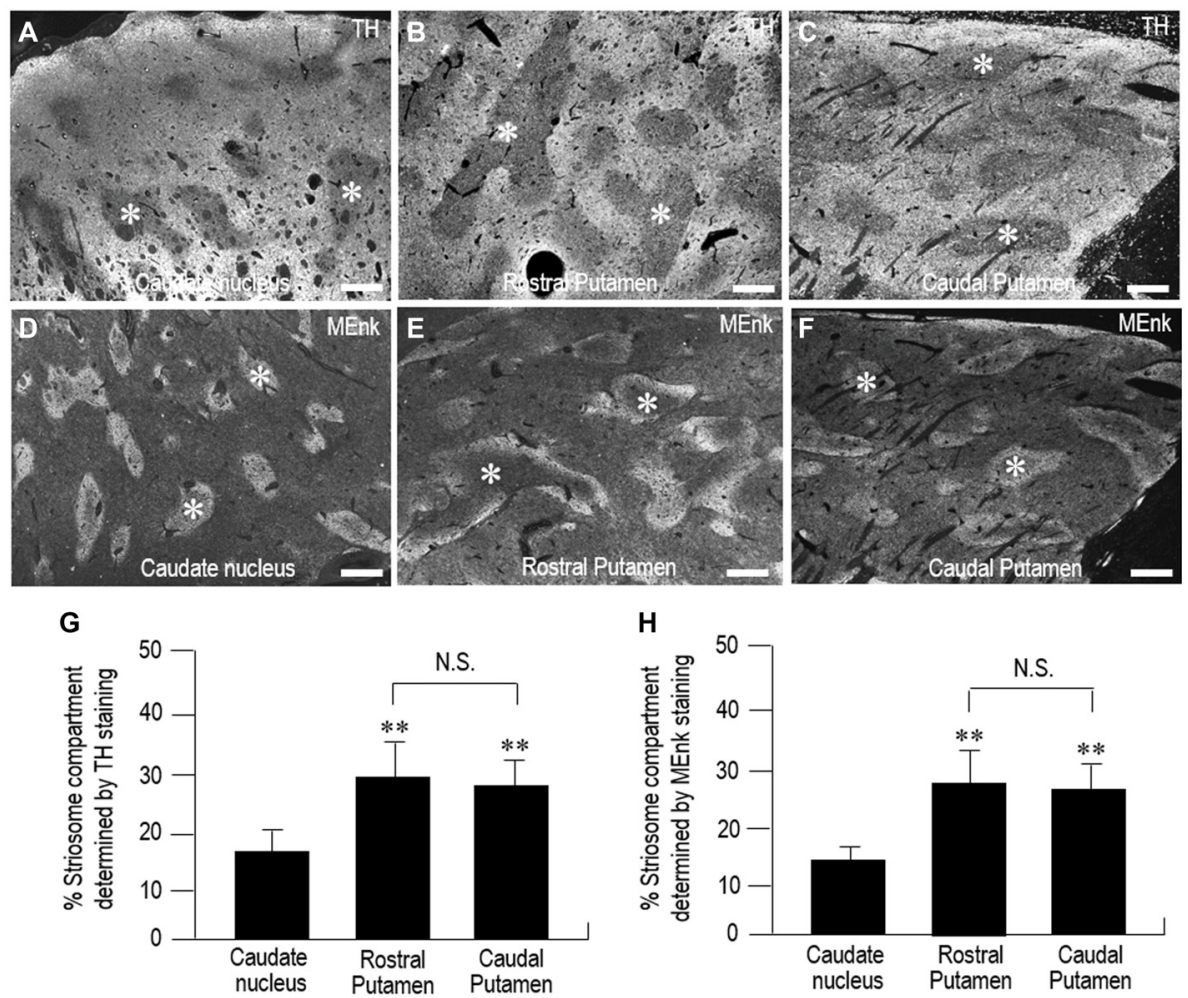

FIGURE 8 | Morphometric analysis of the percentage of the striatum occupied by the striosome compartment in the human neostriatum. (A-F) Gray-scale-converted microscopic images of striatal areas stained with fluorescence for TH (A-C) and MEnk (D-F) in the CN (A,D), rostral putamen (B,E), and caudal putamen (C,F). Asterisks indicate examples of striosomes. Scale bars: $1 \mathrm{~mm}$. (G) Measurements of the percentage of the striatum occupied by the striosome compartment identified by $\mathrm{TH}$-immunostaining in the $\mathrm{CN}$, rostral putamen, and caudal putamen. Data represent means $\pm \mathrm{SEM}$ (bars), $n=25$. $*$ indicates $P<0.01$ vs. CN; N.S. (not significant) indicates $P>0.05$, Rostral Putamen vs. Caudal Putamen. (H) Measurements of the percentage of the striatum occupied by the striosome compartment identified by MEnk-immunostaining in the $\mathrm{CN}$, rostral putamen, and caudal putamen. Data represent means $\pm \mathrm{SEM}$ (bars), $n=25$. **indicates $P<0.01$ vs. CN; N.S. (not significant) indicates $P>0.05$, Rostral Putamen vs. Caudal Putamen.

\section{Putaminal Mosaic Visualized by TH-Immunofluorescence in Human Brains}

Specific immunoreactivity for TH in the human neostriatum was also identified by our IHC protocols using fluorescence. In a photomontage of the striatum stained with Cyanine 3 for $\mathrm{TH}$ (Figure 6A), mosaic patterns were clearly seen in both the $\mathrm{CN}$ and putamen, as shown in Figure 2. Microscopic images with low magnification also revealed the compartmentalized distribution of TH labeling in the CN (Figure 6B) and putamen (Figure 6C). At higher-magnification, abundant $\mathrm{TH}$-immunoreactive fibers and puncta were seen in the matrix (Figure 6D), but less so in the striosomes (Figure 6E).

Double immunofluorescence staining also revealed that $\mathrm{TH}$ immunoreactivity was sparse in the MEnk-enriched striosomes in the $\mathrm{CN}$ (Figures $7 \mathbf{A}, \mathbf{B}$ ) and putamen (Figures $7 \mathrm{C}, \mathbf{D}$ ). At higher-magnification, the margins of the TH-poor zones closely corresponded with the outer margins of the MEnk-rich zones (Figures 7E-G). Within the striosomes, there exist specialized zones rimming the striosomes, which are referred to as "annular" or "striocapsular" zones (Graybiel et al., 1981; Gerfen et al., 1985; Jakab et al., 1996; Holt et al., 1997; Brimblecombe and Cragg, 2015). These express higher levels of MEnk than the core (center) zones, as depicted in Figure 7H. Based on the findings shown here, it is likely that TH immunoreactivity is diffusely distributed within the striosomes, with no apparent difference in the TH-staining intensity between the annular and core zones (Figure $7 \mathrm{H}$ ).

Representative gray-scale images of the striatal areas stained for TH (Figures 8A-C) and MEnk (Figures 8D-F) are shown for the CN (Figures 8A,D), rostral putamen (Figures 8B,E), and caudal putamen (Figures $\mathbf{8 C}, \mathbf{F}$ ). These images (also see, Figures 2, 6) reveal an apparent difference in the striosome-to-matrix ratio among striatal areas. To confirm this visual impression, we carried out a morphometric analysis of the striatal sections. In the striatum stained for $\mathrm{TH}$ (Figure 8G), the percentage of the striatum occupied by the striosome compartment in the $\mathrm{CN}(18.2 \% \pm 3.2 \%)$ was significantly different $(P<0.05)$ from that in both the rostral putamen $(29.8 \% \pm 6.7 \%)$ and caudal putamen $(28.1 \% \pm 5.2 \%)$. In the striatum stained for MEnk (Figure $8 \mathbf{H}$ ), the percentage of the striatum occupied by the striosome compartment in the $\mathrm{CN}(14.0 \% \pm 2.1 \%)$ was significantly different $(P<0.05)$ from that in both the rostral putamen $(29.2 \% \pm 6.4 \%)$ and caudal putamen $(28.1 \% \pm 5.1 \%)$. Thus, the 

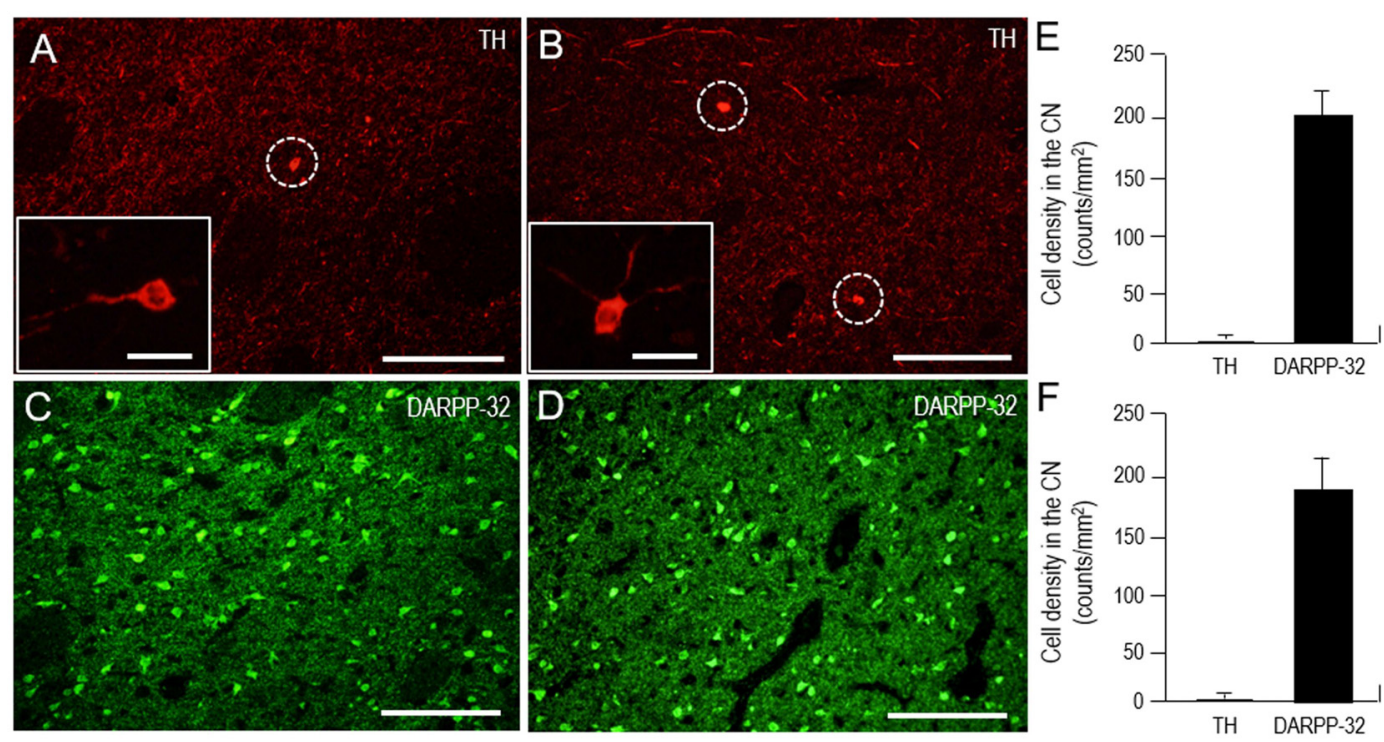

FIGURE 9 | Scarcity of TH-positive interneurons in the human neostriatum. (A-D) Photomicrographs of the CN (A,C) and putamen (B,D) stained for TH (A,B) and DARPP-32 (C,D). The TH-positive cells are indicated by dashed open circles (A,B). Higher-magnification images of the TH-positive cells are also shown in the insets in (A,B). Scale bars: (A-D) $200 \mu \mathrm{m}$, (insets in $\mathbf{A}$ and $\mathbf{B}) 20 \mu \mathrm{m}$. (E,F) Cell density measurements of striatal cells positive for TH or dopamine and cAMP-regulated phosphoprotein of $32 \mathrm{kDa}$ (DARPP-32) in the CN (E) and putamen (F). Values are means $\pm \mathrm{SEM}$ (bars), $n=25$.

striosome-to-matrix ratio of the putamen was $1.5 \sim 2.0$ times that of the $\mathrm{CN}$.

\section{Sparse Distribution of TH-Expressing Interneurons in the Human Neostriatum}

It is known that the mammalian striatum contains a distinguished subgroup of GABAergic interneurons that express TH (for review see, Silberberg and Bolam, 2015). In this study, we also identified the TH-positive cells in both the $\mathrm{CN}$ and putamen (Figure 9). However, cell density analysis (Figures $\mathbf{9 E}, \mathbf{F}$ ) revealed that the $\mathrm{TH}$ cells were only sparsely distributed in the $\mathrm{CN}(1.8 \pm 1.1$ cells $\left./ \mathrm{mm}^{2}\right)$ and putamen $\left(1.6 \pm 1.0\right.$ cells $\left./ \mathrm{mm}^{2}\right)$, while striatal cells positive for DARPP-32, a marker for medium spiny neurons (Okita et al., 2012), were abundantly found in the $\mathrm{CN}\left(201 \pm 22\right.$ cells $\left./ \mathrm{mm}^{2}\right)$ and putamen $\left(192 \pm 31\right.$ cells $\left./ \mathrm{mm}^{2}\right)$.

\section{DISCUSSION}

In this study, we showed an immunohistochemical evidence that $\mathrm{TH}$ is compartmentally distributed in both the $\mathrm{CN}$ and putamen in FFPE human autopsy brains. By means of the serial section analysis and the double fluorescent labeling technique, the present study indicates that $\mathrm{TH}$ is enriched in the matrix compartment relative to the striosomes at the striatal levels from the rostral to the caudal throughout. We suggest that in the entire neostriatum, $\mathrm{TH}$ immunoreactivity forms the distinct striosome-matrix configurations in the same manner. This notion may contradict the previous report indicating that in the human striatum, striosomes are largely devoid of $\mathrm{TH}$ at rostral striatal levels while the inverse is found caudally (Prensa et al., 1999).

$\mathrm{TH}$ is highly concentrated in the neostriatum, where nearly all of it is expressed in axons of the dopaminergic nigrostriatal afferents. However, it has so far been known that in the mammalian striatum, there exists a subset of GABAergic interneurons that express TH (Silberberg and Bolam, 2015), although their roles in striatal dopamine systems have not yet been determined (Xenias et al., 2015). This means that striatal $\mathrm{TH}$ labeling is composed of not only the TH-positive afferents arising from the $\mathrm{SNc}$ but also the $\mathrm{TH}$-immunoreactive products of such interneurons. Indeed, we here identified the TH-positive cells in the human neostriatum (Figure 9). In agreement with the previous report (Bernácer et al., 2012), our results, however, documented that the $\mathrm{TH}$ cells were only scarcely distributed in both the $\mathrm{CN}$ and putamen. The sparse density of the THpositive cells casts doubts about their contribution to the mosaic organization of $\mathrm{TH}$ labeling in the human neostriatum.

Among striatal neurons, striosomal cells are unique because they send their GABAergic inhibitory projections directly or indirectly to the $\mathrm{SNc}$, which contains dopaminergic neurons that project back to both the striosome and matrix compartments (Gerfen, 1984; Jiménez-Castellanos and Graybiel, 1989; Tokuno et al., 2002; Fujiyama et al., 2011; Watabe-Uchida et al., 2012). Accordingly, the striosome compartment could exert global control over striatal dopamine signals by inhibiting the activity of nigral dopaminergic cells (Crittenden and Graybiel, 2011). Considering possible mechanisms that underlie the inhomogeneous organization of $\mathrm{TH}$ immunoreactivity in the striatum of mature human brains, Graybiel et al. (1987) suggested an involvement of presynaptic differences between the striosome and matrix compartments in enzymatic regulation 
of dopamine content. We here showed that in the neostriatal sections stained for $\mathrm{TH}$, the striosome-to-matrix ratio of the putamen is significantly higher $(P<0.05)$ than that of the $\mathrm{CN}$ (Figure 8). Taken together, we suggest that there might be a difference between the $\mathrm{CN}$ and putamen in the compartment-specific homeostatic regulation of striatal dopaminergic activities.

Given the evidence the patch (striosome) and matrix compartments comprised about $15 \%$ and $85 \%$ of the striatal volume, respectively, in the different species that included rat, rhesus monkey, and human, Johnston et al. (1990) suggested that a relatively constant ratio of $15 \%$ patch to $85 \%$ matrix area is maintained across mammalian species including humans. However, they also noted a slight, but significant increase (1.7 times) in the percentage of the striatum occupied by the striosome compartment from rat, through rhesus monkey, to human striatum (Johnston et al., 1990). Moreover, they also described that averaged across species, the rostral striatal sections were slightly richer in patch compartment (17\%) than the caudal sections (9.8\%) (Johnston et al., 1990). Our present study showed that in the human neostriatal sections stained for MEnk, the percentage of the striatum occupied by the striosome compartment in the $\mathrm{CN}(14.0 \%)$ was significantly different $(P<0.05)$ from that in both the rostral putamen $(29.2 \%)$ and caudal putamen $(28.1 \%)$. This indicates that the striosome-tomatrix ratio of the putamen was about 2.0 times that of the $\mathrm{CN}$ in the human neostriatum. In view of these observations, we posit that a species and regional difference of the small degree in the striosome-to-matrix ratio could be found in the striatum of mammals.

The putamen plays a critical role in the basal gangliathalamocortical circuit that regulates our voluntary movements and motor learning. Further anatomical and physiological research on the putamen is, therefore, important for elucidating the pathogenesis and symptomatology of human movement disorders. The putamen also serves as the most suitable site for the intrastriatal application of dopamine-producing transplants

\section{REFERENCES}

Albin, R. L., Young, A. B., and Penney, J. B. (1989). The functional anatomy of basal ganglia disorders. Trends Neurosci. 12, 366-375. doi: 10.1016/01662236(89)90074-X

Alexander, G. E., Crutcher, M. D., and DeLong, M. R. (1990). Basal gangliathalamocortical circuits: parallel substrates for motor, oculomotor, "prefrontal" and "limbic" functions. Prog. Brain Res. 85, 119-146. doi: 10.1016/s00796123(08)62678-3

Alexander, G. E., DeLong, M. R., and Strick, P. L. (1986). Parallel organization of functionally segregated circuits linking basal ganglia and cortex. Annu. Rev. Neurosci. 9, 357-381. doi: 10.1146/annurev.neuro.9.1.357

Amemori, K., Gibb, L. G., and Graybiel, A. M. (2011). Shifting responsibility: the importance of striatal modularity to reinforcement learning in uncertain environments. Front. Hum. Neurosci. 5:47. doi: 10.3389/fnhum.2011. 00047

Bernácer, J., Prensa, L., and Giménez-Amaya, J. M. (2012). Distribution of GABAergic interneurons and dopaminergic cells in the functional territories of the human striatum. PLoS One 7:e30504. doi: 10.1371/journal.pone.0030504

Bolam, J. P., Izzo, P. N., and Graybiel, A. M. (1988). Cellular substrate of the histochemically defined striosome/matrix system of the caudate nucleus: a in PD patients (Lindvall, 2015), as previously suggested (Kish et al., 1988). There is a growing body of evidence that striosomematrix dopaminergic systems might be involved in the diseasespecific striatal pathology and symptoms of multiple human movement disorders (Crittenden and Graybiel, 2011). Indeed, human postmortem analyses have shown compartment-specific pathology in the striatum of patients with movement disorders, such as Huntington's disease (OMIM143100; Ferrante et al., 1987; Goto et al., 1989b; Goto and Hirano, 1990a; Morton et al., 1993; Hedreen and Folstein, 1995; Tippett et al., 2007), multiple system atrophy (OMIM146500) of the parkinsonian type (Goto and Hirano, 1990b; Sato et al., 2007), and Xlinked dystonia-parkinsonism (OMIM314250; Goto et al., 2005, 2013). In this study, we performed an IHC study on FFPE tissues from autopsied human brains, and disclosed that striatal dopaminergic innervations labeled for $\mathrm{TH}$ are organized into discrete striosome-matrix configurations in the putamen. Our present findings provide anatomical evidence supporting the intriguing concept that compartment-specific dysfunction of dopamine-related neural circuits might underlie the genesis of human movement disorders.

\section{AUTHOR CONTRIBUTIONS}

SG contributes to the conception or design of the work; and the acquisition, analysis, and interpretation of data for the work. SG wrote the manuscript. RM contributes to the conception or design of the work; and the acquisition, analysis, and interpretation of data for the work.

\section{ACKNOWLEDGMENTS}

This work was supported in part by grants from the Ministry of Education, Culture, Sports, Science, and Technology of Japan (grants-in-aid for Scientific Research no. 24390223, 26461272, and 26430054).

combined Golgi and immunocytochemical study in cat and ferret. Neuroscience 24, 853-875. doi: 10.1016/0306-4522(88)90073-5

Brimblecombe, K. R., and Cragg, S. J. (2015). Substance P weights striatal dopamine transmission differently within the striosome-matrix axis. J. Neurosci. 35, 9017-9023. doi: 10.1523/JNEUROSCI.0870-15.2015

Ciliax, B. J., Drash, G. W., Staley, J. K., Haber, S., Mobley, C. J., Miller, G. W., et al. (1999). Immunocytochemical localization of the dopamine transporter in human brain. J. Comp. Neurol. 409, 38-56. doi: 10.1002/(sici)10969861(19990621)409:1<38::aid-cne4>3.0.co;2-1

Crittenden, J. R., and Graybiel, A. M. (2011). Basal ganglia disorders associated with imbalances in the striatal striosome and matrix compartments. Front. Neuroanat. 5:59. doi: 10.3389/fnana.2011.00059

DeLong, M. R. (1990). Primate models of movement disorders of basal ganglia origin. Trends Neurosci. 13, 281-285. doi: 10.1016/0166-2236(90) 90110-v

Ferrante, R. J., and Kowall, N. W. (1987). Tyrosine hydroxylase-like immunoreactivity is distributed in the matrix compartment of normal human and Huntington's disease striatum. Brain Res. 416, 141-146. doi: 10. 1016/0006-8993(87)91506-x

Ferrante, R. J., Kowall, N. W., Beal, M. F., Martin, J. B., Bird, E. D., and Richardson, E. P., Jr. (1987). Morphologic and histochemical characteristics of a spared 
subset of striatal neurons in Huntington's disease. J. Neuropathol. Exp. Neurol. 46, 12-27. doi: 10.1097/00005072-198701000-00002

Fujiyama, F., Sohn, J., Nakano, T., Furuta, T., Nakamura, K. C., Matsuda, W., et al. (2011). Exclusive and common targets of neostriatofugal projections of rat striosome neurons: a single neuron-tracing study using a viral vector. Eur. J. Neurosci. 33, 668-677. doi: 10.1111/j.1460-9568.2010.07564.x

Gerfen, C. R. (1984). The neostriatal mosaic: compartmentalization of corticostriatal input and striatonigral output systems. Nature 311, 461-464. doi: $10.1038 / 312172 \mathrm{a} 0$

Gerfen, C. R. (1992). The neostriatal mosaic: multiple levels of compartmental organization in the basal ganglia. Annu. Rev. Neurosci. 15, 285-320. doi: 10. 1146/annurev.neuro.15.1.285

Gerfen, C. R., Baimbridge, K. G., and Miller, J. J. (1985). The neostriatal mosaic: compartmental distribution of calcium-binding protein and parvalbumin in the basal ganglia of the rat and monkey. Proc. Natl. Acad. Sci. U S A 82, 8780-8784. doi: 10.1073/pnas.82.24.8780

Gerfen, C. R., Herkenham, M., and Thibault, J. (1987). The neostriatal mosaic: II. Patch- and matrix-directed mesostriatal dopaminergic and non-dopaminergic systems. J. Neurosci. 7, 3915-3934.

Goto, S., and Hirano, A. (1990a). Synaptophysin expression in the striatum in Huntington's disease. Acta Neuropathol. 80, 88-91. doi: 10.1007/bf00294227

Goto, S., and Hirano, A. (1990b). Inhomogeneity of the putaminal lesion in striatonigral degeneration. Acta Neuropathol. 80, 204-207. doi: 10. $1007 / \mathrm{bf} 00308925$

Goto, S., Hirano, A., and Matsumoto, S. (1989a). Subdivisional involvement of nigrostriatal loop in idiopathic Parkinson's disease and striatonigral degeneration. Ann. Neurol. 26, 766-770. doi: 10.1002/ana.410260613

Goto, S., Hirano, A., and Rojas-Corona, R. R. (1989b). An immunohistochemical investigation of the human neostriatum in Huntington's disease. Ann. Neurol. 25, 298-304. doi: 10.1002/ana.410250315

Goto, S., Kawarai, T., Morigaki, R., Okita, S., Koizumi, H., Nagahiro, S., et al. (2013). Defects in the striatal neuropeptide Y system in X-linked dystoniaparkinsonism. Brain 136, 1555-1567. doi: 10.1093/brain/awt084

Goto, S., Lee, L. V., Munoz, E. L., Tooyama, I., Tamiya, G., Makino, S., et al. (2005). Functional anatomy of the basal ganglia in X-linked recessive dystoniaparkinsonism. Ann. Neurol. 58, 7-17. doi: 10.1002/ana.20513

Goto, S., Matsumoto, S., Ushio, Y., and Hirano, A. (1996). Subregional loss of putaminal efferents to the basal ganglia output nuclei may cause parkinsonism in striatonigral degeneration. Neurology 47, 1032-1036. doi: 10.1212/wnl.47.4. 1032

Goto, S., Morigaki, R., Okita, S., Nagahiro, S., and Kaji, R. (2015). Development of a highly sensitive immunohistochemical method to detect neurochemical molecules in formalin-fixed and paraffin-embedded tissues from autopsied human brains. Front. Neuroanat. 9:22. doi: 10.3389/fnana.2015. 00022

Goto, S., Nagahiro, S., and Kaji, R. (2010). "Striosome-matrix pathology of dystonias: a new hypothesis for dystonia genesis," in Dystonia: Causes, Symptoms and Treatment, eds J. Kurstot and M. Forsstrom (New York, NY: Nova Science Publishers), 1-22.

Graybiel, A. M. (1990). Neurotransmitters and neuromodulators in the basal ganglia. Trends Neurosci. 13, 244-254. doi: 10.1016/0166-2236(90)90104-i

Graybiel, A. M. (2008). Habits, rituals and the evaluative brain. Annu. Rev. Neurosci. 31, 359-387. doi: 10.1146/annurev.neuro.29.051605. 112851

Graybiel, A. M., Canales, J. J., and Capper-Loup, C. (2000). Levodopa-induced dyskinesias and dopamine-dependent stereotypies: a new hypothesis. Trends Neurosci. 23, S71-S77. doi: 10.1016/s1471-1931(00)00027-6

Graybiel, A. M., Hirsch, E. C., and Agid, Y. A. (1987). Differences in tyrosine hydroxylase-like immunoreactivity characterize the mesostriatal innervation of striosomes and extrastriosomal matrix at maturity. Proc. Natl. Acad. Sci. U S A 84, 303-307. doi: 10.1073/pnas.84.1.303

Graybiel, A. M., and Ragsdale, C. W., Jr. (1978). Histochemically distinct compartments in the striatum of human, monkeys and cat demonstrated by acetylcholinesterase staining. Proc. Natl. Acad. Sci. U S A 75, 5723-5726. doi: 10. 1073/pnas.75.11.5723

Graybiel, A. M., Ragsdale, C. W., Jr., Yoneoka, E. S., and Elde, R. P. (1981). An immunohistochemical study of enkephalins and other neuropeptides in the striatum of the cat with evidence that the opiate peptides are arranged to form mosaic patterns in register with the striosomal compartments visible by acetylcholinesterase staining. Neuroscience 6, 377-397. doi: 10.1016/03064522(81)90131-7

Hedreen, J. C., and Folstein, S. E. (1995). Early loss of neostriatal striosome neurons in Huntington's disease. J. Neuropathol. Exp. Neurol. 54, 105-120. doi: 10.1097/00005072-199501000-00013

Hirsch, E., Graybiel, A. M., and Agid, Y. A. (1988). Melanized dopaminergic neurons are differentially susceptible to degeneration in Parkinson's disease. Nature 334, 345-348. doi: 10.1038/334345a0

Holt, D. J., Graybiel, A. M., and Saper, C. B. (1997). Neurochemical architecture of the human striatum. J. Comp. Neurol. 384, 1-25. doi: 10.1002/(sici)10969861(19970721)384:1<1::aid-cnel>3.0.co;2-5

Jakab, R. L., Hazrati, L. N., and Goldman-Rakic, P. (1996). Distribution and neurochemical character of substance $\mathrm{P}$ receptor (SPR)-immunoreactive striatal neurons of the macaque monkey: accumulation of SP fibers and SPR neurons and dendrites in "striocapsules" encircling striosomes. J. Comp. Neurol. 369, 137-149. doi: 10.1002/(sici)1096-9861(19960520)369:1<137::aidcne10>3.0.co;2-o

Jimenez-Castellanos, J., and Graybiel, A. M. (1987). Subdivisions of the dopaminecontaining A8-A9-A10 complex identified by their differential mesostriatal innervation of striosomes and extrastriosomal matrix. Neuroscience 23, 223-242. doi: 10.1016/0306-4522(87)90285-5

Jiménez-Castellanos, J., and Graybiel, A. M. (1989). Compartmental origins of striatal efferent projections in the cat. Neuroscience 32, 297-321. doi: 10. 1016/0306-4522(89)90080-8

Johnston, J. G., Gerfen, C. R., Haber, S. N., and van der Kooy, D. (1990). Mechanisms of striatal pattern formation: conservation of mammalian compartmentalization. Brain Res. Dev. Brain Res. 57, 93-102. doi: 10. 1016/0165-3806(90)90189-6

Kish, S. J., Shannak, K., and Hornykiewicz, O. (1988). Uneven pattern of dopamine loss in the striatum of patients with idiopathic Parkinson's disease. Pathophysiologic and clinical implications. N. Engl. J. Med. 318, 876-880. doi: 10.1056/nejm198804073181402

Langer, L. F., and Graybiel, A. M. (1989). Distinct nigrostriatal projection systems innervate striosomes and matrix in the primate striatum. Brain Res. 498, 344-350. doi: 10.1016/0006-8993(89)91114-1

Lindvall, O. (2015). Treatment of Parkinson's disease using cell transplantation. Philos. Trans. R. Soc. Lond. B Biol. Sci. 370:20140370. doi: 10.1098/rstb.2014. 0370

Matsuda, W., Furuta, T., Nakamura, K. C., Hioki, H., Fujiyama, F., Arai, R., et al. (2009). Single nigrostriatal dopaminergic neurons form widely spread and highly dense axonal arborizations in the neostriatum. J. Neurosci. 29, 444-453. doi: 10.1523/JNEUROSCI.4029-08.2009

Morigaki, R., and Goto, S. (2015). Postsynaptic density protein 95 in the striosome and matrix compartments of the human neostriatum. Front. Neuroanat. 9:154. doi: 10.3389/fnana.2015.00154

Morton, A. J., Nicholson, L. F., and Faull, R. L. (1993). Compartmental loss of NADPH diaphorase in the neuropil of the human striatum in Huntington's disease. Neuroscience 53, 159-168. doi: 10.1016/0306-4522(93) 90294-p

Moss, J., and Bolam, J. P. (2008). A dopaminergic axon lattice in the striatum and its relationship with cortical and thalamic terminals. J. Neurosci. 28, 11221-11230. doi: 10.1523/JNEUROSCI.2780-08.2008

Okita, S., Morigaki, R., Koizumi, H., Kaji, R., Nagahiro, S., and Goto, S. (2012). Cell type-specific localization of optineurin in the striatal neurons of mice: implications for neuronal vulnerability in Huntington's disease. Neuroscience 202, 363-370. doi: 10.1016/j.neuroscience.2011. 11.059

Prensa, L., Cossette, M., and Parent, A. (2000). Dopaminergic innervation of human basal ganglia. J. Chem. Neuroanat. 20, 207-213. doi: 10.1016/s08910618(00)00099-5

Prensa, L., Giménez-Amaya, J. M., and Parent, A. (1999). Chemical heterogeneity of the striosomal compartment in the human striatum. J. Comp. Neurol. 413 603-618. doi: 10.1002/(SICI)1096-9861(19991101)413:4<603::AID-CNE9>3. $0 . \mathrm{CO} ; 2-\mathrm{K}$

Prensa, L., and Parent, A. (2001). The nigrostriatal pathway in the rat: a singleaxon study of the relationship between dorsal and ventral tier nigral neurons and the striosome/matrix striatal compartments. J. Neurosci. 21, 7247-7260. 
Sato, K., Kaji, R., Matsumoto, S., Nagahiro, S., and Goto, S. (2007). Compartmental loss of striatal medium spiny neurons in multiple system atrophy of parkinsonian type. Mov. Disord. 22, 2365-2370. doi: 10.1002/mds.21732

Sato, K., Sumi-Ichinose, C., Kaji, R., Ikemoto, K., Nomura, T., Nagatsu, I., et al. (2008). Differential involvement of striosome and matrix dopamine systems in a transgenic model of dopa-responsive dystonia. Proc. Natl. Acad. Sci. U S A 105, 12551-12556. doi: 10.1073/pnas.0806065105

Silberberg, G., and Bolam, J. P. (2015). Local and afferent synaptic pathways in the striatal microcircuitry. Curr. Opin. Neurobiol. 33, 182-187. doi: 10.1016/j.conb. 2015.05.002

Tippett, L. J., Waldvogel, H. J., Thomas, S. J., Hogg, V. M., van Roon-Mom, W., Synek, B. J., et al. (2007). Striosomes and mood dysfunction in Huntington's disease. Brain 130, 206-221. doi: 10.1093/brain/awl243

Tokuno, H., Chiken, S., Kametani, K., and Moriizumi, T. (2002). Efferent projections from the striatal patch compartment: anterograde degeneration after selective ablation of neurons expressing mu-opioid receptor in rat. Neurosci. Lett. 332, 5-8. doi: 10.1016/s0304-3940(02)00837-6
Watabe-Uchida, M., Zhu, L., Ogawa, S. K., Vamanrao, A., and Uchida, N. (2012). Whole-brain mapping of direct inputs to midbrain dopamine neurons. Neuron 74, 858-873. doi: 10.1016/j.neuron.2012.03.017

Xenias, H. S., Ibáñez-Sandoval, O., Koós, T., and Tepper, J. M. (2015). Are striatal tyrosine hydroxylase interneurons dopaminergic? J. Neurosci. 35, 6584-6599. doi: 10.1523/JNEUROSCI.0195-15.2015

Conflict of Interest Statement: The authors declare that the research was conducted in the absence of any commercial or financial relationships that could be construed as a potential conflict of interest.

Copyright (c) 2016 Morigaki and Goto. This is an open-access article distributed under the terms of the Creative Commons Attribution License (CC BY). The use, distribution and reproduction in other forums is permitted, provided the original author(s) or licensor are credited and that the original publication in this journal is cited, in accordance with accepted academic practice. No use, distribution or reproduction is permitted which does not comply with these terms. 